\title{
ANALISA EFEKTIFITAS BANK SAMPAH SEBAGAI ALTERNATIF PENGELOLAAN SAMPAH DALAM MENCAPAI SMART CITY DI KABUPATEN KULON PROGO
}

\author{
Mike Dewanti ${ }^{1}$, Eko Priyo Purnomo ${ }^{2}$, Lubna Salsabila ${ }^{3}$ \\ 1,2,3Program Studi Ilmu Pemerintahan Universitas Muhammadiyah Yogyakarta \\ Email: mikedewanti03@gmail.com,eko@umy.ac.id, lubna.salsabila@umy.ac.id
}

Article Histori:

Submited: $28 / 12 / 2019$

Editing: $29 / 04 / 2020$

Publish: $30 / 4 / 2020$

\begin{abstract}
This research will focus on analyzing the effectiveness of the waste bank as an alternative to waste management in achieving the concept of smart city in Kulon Progo Regency. The research was conducted to describe how the existence of a garbage bank in Kulon Progo Regency and to analyze how the effectiveness of the waste bank in managing waste in achieving the concept of smart city. This research uses a qualitative method with a descriptive analysis approach. The researcher uses descriptive analysis method, which is an analysis that is intended to explain data from one variable under study. From the research results obtained information that the existence of a garbage bank is experiencing good development because up to 2019 there have been 116 garbage banks. While the effectiveness of the garbage bank has so far been seen to be less effective because it has only been able to manage 10\% of the waste generated. Indeed, waste banks make sprouts of economic value and provide benefits to waste producers but have not overcome the problem of waste. So that the concept of smart city on environmental indicators is still not well achieved by the existence of a garbage bank.
\end{abstract}

Keyword: sampah, smart city, pengelolaan sampah, bank sampah

\section{PENDAHULUAN}

Sebagai salah satu Kabupaten dengan perkembangan ekonomi dan investasi yang cukup pesat karena pembangunan Yogyakarta Internasional Airport, peningkatan penduduk di Kabupaten Kulon Progo juga terjadi. Konsekuensi dari peningkatan penduduk di Kabupaten Kulon Progo akan berimbas pada peningkatan volume sampah karena adanya peningkatan

P-JIAP: Vol. 5 (1) 2020; Dewanti konsumsi masyarakat pula. Seiring dengan pola konsumerisasi masyarakat yang terus meningkat dapat dipastikan juga bahwa tingkat sampah juga akan meningkat (Suryani, 2014). Pertumbuhan penduduk di Kabupaten Kulon Progo yang mengakibatkan meningkatnya tingkat konsumsi masyarakat, dan berdampak pada meningkatnya jumlah sampah. Upaya penanganan sampah masih merupakan 
problem yang harus dicari solusinya oleh pemerintah setempat. Timbunan sampah masih menjadi pemandangan yang dapat dinikmati di beberapa tempat seperti di lahan-lahan kosong, di sekitar pasar, di tepi jalan bahkan di tempat-tempat wisata. Hal tersebut tentunya menjadi nilai minus bagi Kulon Progo yang sedang dalam perkembangan ekonomi yang lebih maju.

Berdasarkan data yang diperoleh dari Badan Pusat Statistik Kabupaten Kulon Progo, dari tahun 2010-2019 telah terjadi peningkatan jumlah penduduk sebanyak 58,188 jiwa sehingga menjadi 447.057 jiwa pada tahun 2019. Peningkatan laju penduduk tersebut tentunya juga dibarengi dengan tingkat konsumsi masyarakat. Pola konsumsi masyarakat yang tinggi tentunya juga akan mengakibatkan jumlah sampah yang dihasilkan akan semakin tinggi.

Menurut data perhitungan dari Dinas Pekerjaan Umum Perumahan dan Kawasan Pemukiman Kabupaten Kulon Progo, sejalan dengan meningkatnya jumlah penduduk di Kabupaten Kulon Progo, volume sampah yang dihasilkan juga terus bertambah, demikian juga dengan ragam sampah yang dihasilkan, baik sampah dari kegiatan domestik (rumah tangga) maupun sampah non domestik (perdagangan, pasar dan industri). Di tahun 2018 sendiri, produksi sampah di Kabupaten Kulon Progo berkisar 60.000 ton per tahun (DPUPKP, 2019).

Dengan keadaan tersebut, Pemerintah Kabupaten Kulon Progo yang tengah bergegas dalam upaya mencapai konsep smart city, menggandeng masyarakat umum untuk ikut andil dalam upaya penanganan sampah di Kabupaten Kulon Progo. Bentuk upaya yang dilakukan adalah dengan menciptakan bank sampah. Kehadiran bank sampah memberikan harapan lebih efisien dan efektif karena keterlibatan warga secara aktif dengan harapan volume sampah dapat berkurang. Kepala Dinas Lingkungan Hidup (DLH) Kulon Progo, Suharjoko mengatakan, jumlah bank sampah di Kulon Progo pada tahun 2019 telah mencapai lebih dari 100 unit, dengan jumlah nasabat lebih dari 2.000 orang. Cukup tingginya kesadaran masyarakat dalam permasalah sampah dan keberadaan bank sampah diharapkan mampu mengatasi persoalan sampah sekaligus menciptakan lingkungan bersih. Kehadiran bank sampah merupakan bentuk kearifan lokal yang menunjukkan bahwa masyarakat sudah memiliki kesadaran dan kepedulian untuk mengubah sampah bernilai lebih ekonomis.

Program bank sampah pada konsepnya merupakan program yang dilakukan untuk mendorong masyarakat untuk mau melakukan pemilahan sampah. Implementasi dari program bank sampah ini mampu memberikan wujud nyata menambah pendapatan keluarga sekaligus sebagai upaya untuk menyelamatkan lingkungan masyarakat dalam manajemen operasi bank sampah dan investasi dalam bentuk tabungan. Untuk menjadi kota cerdas (smart city) ditinjau dari komponen smart environment tentu butuh tata kelola kota, diantaranya:1) lingkungan dikelola secara sustainable; 2) mengurangi penggunaan energy, melalui inovasi teknologi; dan 3) konservasi energi dan daur ulang material. Pengelolaan lingkungan bersih, sehat dan nyaman, akan sangat mendukung terwujudnya smart city, karena lingkungan bersih, sehat dan nyamaadalah bagian komponen dari smart city, yaitu smart environment.

Untuk mewujudkan lingkungan bersih, sehat dan nyaman, bank sampah hadir sebagai alternatif memberikan solusi pengelolaan sampah agar minim sampah. Maka dari itu, tujuan penelitian ini, untuk mendeskripsikan keberadaan 
perkembangan bank sampah dan efektivitas bank sampah sebagai pilihan pengelolaan sampah di Kabupaten Kulon Progo.

\section{KAJIAN LITERATUR \\ Sampah}

Sampah adalah sesuatu yang tidak dipergunakan lagi, yang tidak dapat dipakai lagi, yang tidak disenangi dan harus dibuang, maka sampah tentu saja harus dikelola dengan sebaik-baiknya, sedemikian rupa, sehingga hal-hal yang negatif bagi kehidupan tidak sampai terjadi (Azwar, 1990; Suryani, 2014). Sampah diklasifikasikan menjadi sampah basah, sampah kering, sampah abu dan arang yang berasal dari sisa pembakaran, sampah yang berasal dari bangkai hewan, sampah atau kotoran yang berserakan di sepanjang jalan, dan sampah berasal dari kegiatan industry (Fadhilah et al., 2011). Berdasarkan sifatnya, sampah kota dapat dibagi menjadi dua yaitu Sampah organic dan sampah anorganik. Sampah organik adalah sampah yang mudah terdegradasi sehingga mudah terurai. Contohnya : sampah sayuran, daundaunan, bagian tubuh hewan, sisa makanan, kertas, kayu dan lain-lain. Sampah anorganik adalah sampah yang sulit terdegradasi sehingga sulit terurai. Contohnya : plastik, kaca, logam, kaleng dan lain-lain (Anggraini, 2012).

\section{Smart City}

Konsep dasar Smart City adalah mewujudkan sebuah lingkungan bagi masyarakat yang efisien dan memberikan rasa aman (Patel \& Padhya, 2014 ; Lakista, 2019). Smart city membuat inovasi yang dapat meningkatkan pelayanan bagi masyarakat dan meningkatkan keterlibatan masyarakat dalam membuat suatu kota menjadi layak huni tangguh dan mampu menggunakan perkembangan teknologi saat ini. (Hariadi, 2016; Lakista, 2019). Smart City/Kota cerdas melakukan pembangunan kotanya dengan cara melihat ke depan dengan mempertimbangan isu-isu seperti kontribusi, ketegasan diri, kemandirian, dan kesadaran. Konsep kota yang cerdas memiliki atribut atau dimensi, yaitu : Pemerintahan yang cerdas (Smart Government), Lingkungan yang cerdas (Smart Environment), Masyarakat cerdas (Smart People), Ekonomi cerdas (Smart Economy), Kehidupan cerdas (Smart Living), Mobilitas cerdas (Smart Mobility) (Arjita, 2017). Indikator smart environment yang merupakan kompilasi antara Boyd Cohen, ISO, dan UNECE terdiri dari energi listrik, energi terbarukan, emisi gas rumah kaca, kualitas ari, sampah, air bersih, ketahanan iklim, penataan ruang, RTH, dan permukiman ( Wahyudi, 2019). Maka dari itu, pengelolaan sampah yang baik menjadi salah satu indikator yang harus dipenuhi guna mencapai tujuan dari Smart City.

\section{Pengelolaan Sampah}

Pengelolaan sampah adalah semua kegiatan yang dilakukan untuk menangani sampah sejak ditimbulkan sampai dengan pembuangan akhir. Secara garis besar, kegiatan pengelolaan sampah meliputi: pengendalian timbulan sampah, pengumpulan sampah, pengangkutan, pengolahan dan pembuangan akhir. Penanganan sampah tidaklah mudah, melainkan sangat kompleks, karena mencakup aspek teknis, ekonomi dan sosiopolitis. Pengelolaan sampah adalah usaha untuk mengatur atau mengelola sampah dari proses pewadahan, pengumpulan, pemindahan, pengangkutan, pengolahan, hingga pembuangan akhir (Suryani, 2014). Sistem pengolahan sampah yang baik dapat dilakukan dengan cara Implementasi konsep zero waste secara bertahap dan berkelanjutan, Pengembangan sistem penyangga industri berbasis sampah serta distribusi dan pemasaran produk dan 
Pengembangan Museum Sampah (Malina \& Muchtar, 2017).

Penerapan konsep Zero Waste City dengan pengelolaan sampah yang baik harus menjalankan lima prinsip utama yaitu melibatkan masyakarat, kemandirian, efisiensi, pelestarian lingkungan, dan keterpaduan (Suswantini, 2018). Pemberdayaan masyarakat dalam pengelolaan sampah dan limbah melalui penyuluhan dan pelatihan pengelolaan sampah menjadi barang yang lebih bermanfaat harus dilakukan kepada masyarakat agar masyarakat tidak hanya tergantung kepada dinas terkait pengelolaan sampah karena masyarakat dapat mengelola sampah sendiri menjadi bahan yang bernilai ekonomis sehingga tercipta smart environment sekaligus smart people (Mudayana, Yuli, \& Suwartini, 2019).

\section{Bank Sampah}

Bank Sampah merupakan alternatif solusi dalam mengatasi masalah sampah di perkotaan, pengembangan bank sampah merupakan kegiatan bersifat social engineering yang mengajarkan masyarakat untuk memilah sampah serta menumbuhkan kesadaran masyarakat dalam pengolahan sampah. (Ridley-Duff dan Bull, 2011; Asteria, 2015). Menurut Peraturan Menteri Negara Lingkungan Hidup No. 13 Tahun 2012 bank sampah adalah tempat pemilahan dan pengumpulan sampah yang dapat didaur ulang dan/atau diguna ulang yang memiliki nilai ekonomi. Bank Sampah adalah salah satu alternatif mengajak warga peduli dengan sampah, yang konsepnya mungkin dapat dikembangkan di daerahdaerah lainya (Ulfah, 2016). Pembentukan bank sampah harus diintegrasikan dengan gerakan program $4 \mathrm{R}$ sehingga warga akan memperoleh manfaat langsung, tidak hanya secara ekonomi, juga terwujudnya kesehatan lingkungan, dengan kondisi komunitas yang bersih, hijau, nyaman, dan sehat (Asteria, 2015). Manfaat dari keberadaan bank sampah adalah meningkatkan ekonomi masyarakat, terciptanya lingkungan yang bersih sehingga tingkat kesehatan masayrakat juga semakin baik, dan juga terjalin interaksi social yang lebih baik diantara masyarakat (Novianty, 2013).

\section{METODE PENELITIAN}

Jenis penelitian yang dipakai dalam tulisan ini adalah jenis penelitian deskriptif dengan pendekatan kualitatif. Pendekatan deskriptif kualitatif adalah pendekatan penelitian dengan cara mengumpulkan data-data yang bersumber dari hasil wawancara, catatan lapangan, video tape, foto, catatan, dokumentasi pribadi, atau memo dan data lainnya. Data yang dikumpulkan berupa data kata-kata, gambar-gambar dan bukan angka (Moleong, 2005; Mochammad, 2019) Penelitian yang bersifat deskriptif bertujuan untuk membuat deskripsi, gambaran atau lukisan secara sistematis, factual, dan akurat mengenai fakta, sifat serta hubungan antara fenomena yang diselidiki (Nazir, 2005; Mochammad, 2019). Analisi menggunakan teknik analisis model interaktif yang dikembangkan oleh Miles dan Hubberman meliputi tiga tahap yaitu reduksi data, penyajian data dan kesimpulan (Moleong, 2010; Suhendri \& Priyo Purnomo, 2017).

\section{HASIL DAN PEMBAHASAN Sampah di Kabupaten Kulon Progo}

Sampah yang tidak tertangani dengan baik tentunya memberikan efek yang buruk bagi masalah social dan lingkungan. Dengan mempertimbangkan volume sampah yang kian waktu kian bertambah, diperlukan upaya yang maksimal dalam pengelolaan sampah. Kebijakan 
pengelolaan sampah di wilayah perkotaaan di atur dalam Undang-Undang Nomor 18 Tahun 2008 tentang Pengelolaan Sampah. Hal ini merupakan suatu tonggak baru bagi masyarakat untuk solusi penanganan permasalahan sampah. Pengelolaan sampah difokuskan pada dua kegiatan, dengan cara:

1. Meminimalisir sampah, dengan perilaku minim sampah (reduce), pemanfaatan lagi (reuse), dan proses kembali (recycle)

2. Pengolahan sampah, meliputi kegiatan:

a. Dipilah berdasarkan karakter sampah b. Dikumpulkan dan sementara ditampung di bank sampah

c. Diangkut dengan memindahkan sampah ke TPA

d. Pemroresan untuk diubah sifatnya sampah

Menurut Dinas Lingkungan Hidup Kulon Progo pada taun 2017 komposisi sampah yang paling mendominasi di Kulon Progo adalah sampah organik yang mencapai $67,18 \%$. Sementara untuk data komposisi sampah yang lain disajikan dalam Tabel 1. Komposisi Sampah di Kulon Progo.

Tabel 1.

Komposisi Sampah di Kulon Progo

\begin{tabular}{rlc}
\hline No & Jenis Sampah & Komposisi \\
\hline 1 & Organik & $67,18 \%$ \\
2 & Kertas & $12,6 \%$ \\
3 & Palstik & $1,68 \%$ \\
4 & Kain & $0,67 \%$ \\
5 & Kayu & $0,21 \%$ \\
6 & Gelas kaca & $0,68 \%$ \\
7 & Lain-lain & $1,11 \%$ \\
\hline
\end{tabular}

Source: Dinas Lingkungan Hidup Kulon Progo

Menurut Dinas Lingkungan Hidup Kabpaten Kulon Progo, setiap harinya, ratarata satu orang di Kulon Progo memproduksi hamper sekitar 0,5 kg sampah perharinya. Jika ditotalkan dengan jumlah warga yang mencapai lebih dari 400.000 jiwa, maka setiap harinya potensi sampah di Kulon Progo dapat mencapai 200 ton. Dengan keadaan tersebut, tentunya permasalahan sampah menjadi permasalahan yang pelik yang sedang dihadapi di Kabupaten Kulon Progo. Jika tidak dilakukan penanganan sampah secara maksimal, maka timbunan sampah akan semakin banyak di Kulon Progo.
Maka dari itu perlu strategi bagaimana caranya agar sampah yang notabene merupakan sumber masalah dapat menjadi sumber manfaat bagi masyarakat. Salah satu strategi yang diambil Dinas Lingkungan Hidup Kabupaten Kulon Progo adalah dengan membentuk bank sampah. Dengan adanya bank sampah diharapkan masyarakat mampu berkontribusi dalam pengelolaan sampah termasuk dalam hal ini pemilahan sampah. Dengan pengelolaan yang baik dan sinergisitas antara masyarakat dengan bank sampah maka sampah non organik yang tidak berguna akan memiliki nilai ekonomis. 


\section{Bank Sampah di Kabupaten Kulon Progo}

Dalam menangani permasalahan sampah yang jumlahnya terus bertambah, Dinas Lingkungan Hidup Kabupaten Kulon Progo mengambil alternatif kebijakan berupa pembentukan bank sampah. Bank sampah yang berada di Kulon progo juga diharapkan mampu mendukung Kabupaten Kulon Progo dalam menuju kota pintar atau smart city. Hal ini karena salah satu indikator dari smart city merumakan smart environment dimana smart environment adalah penciptaan lingkungan yang sehat didukung dengan pemanfaatan teknologi. Maka pengelolaan sampah yang baik adalah hal yang perlu dipenuhi, salah satunya melalui bank sampah.

Kehadiran bank sampah mendapat respon yang positif dari masyarakat. Bank sampah dirasa cukup efektif dalam pengelolaan sampah. Hal ini karena bank sampah melibatkan warga secara aktif. Dengan keterlibatan masyarakat secara aktif menunjukkan kesadaran masyarakat dan hal ini sangat membantu mengatasi permasalahan sampah. Berdasarkan data dari Dinas Lingkungan Hidup Kabupaten Kulon Progo, pada awal tahun 2019, jumlah bank sampah di Kulon progo telah mencapai 116 bank sampah. Jumlah tersebut meliputi bank sampah yang masih beroperasi dan yang mati suri. Selain dapat mengubah sampah menjadi barang yang bernilai ekonomis, bank sampah juga diharapkan mampu menajdi motor penggerak untuk terciptanya smart city yang sedang gencar-gencarnya dicapai Kulon Progo.

\section{Bagan 1.}

Alur Proses Bank Sampah

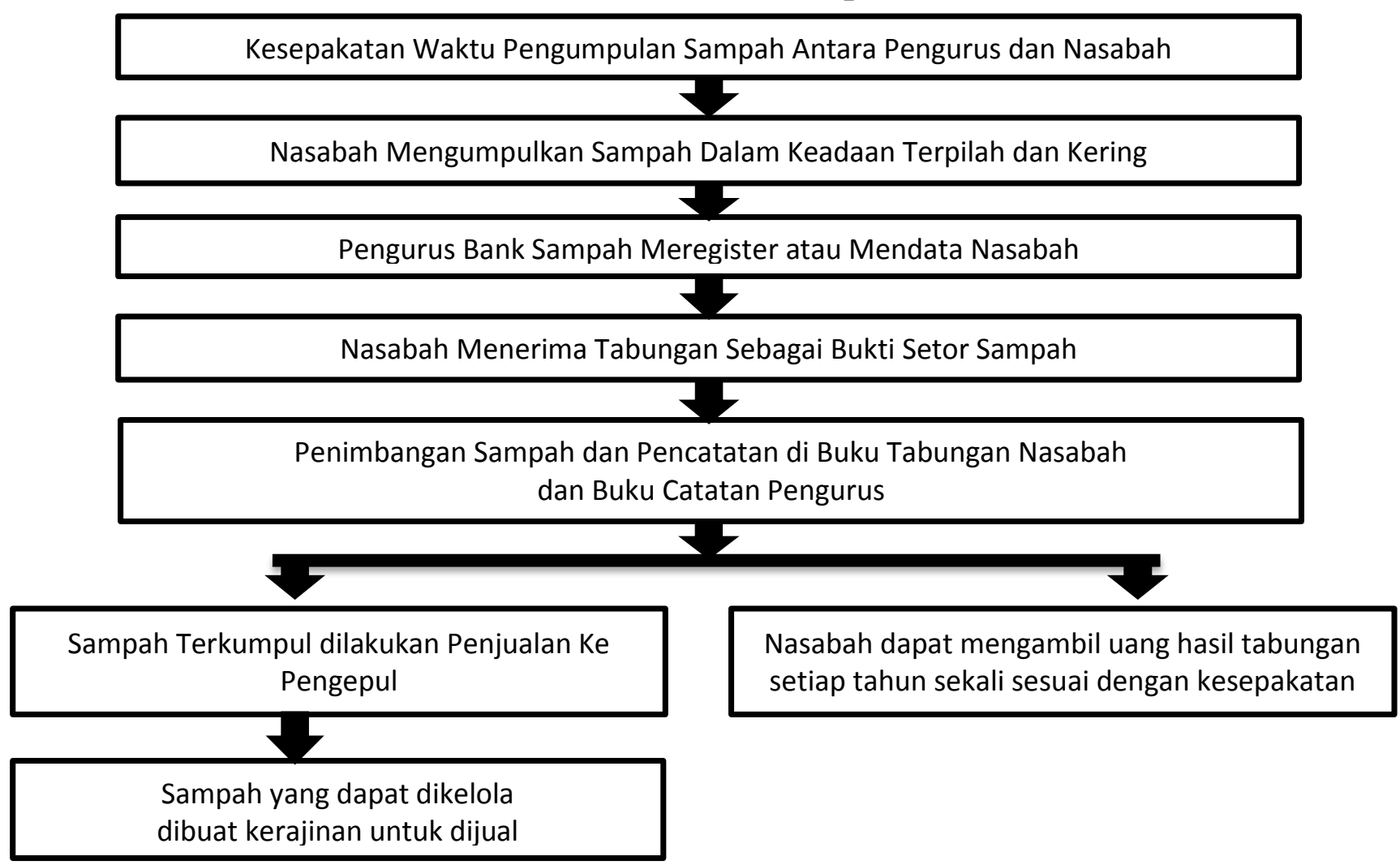

Sumber : Kulonprogokab.go.id, diolah oleh peneliti 
Efektifitas Bank Sampah Sebagai Alternatif Pengelolaan Sampah di Kabupaten Kulon progo

Berbicara mengenai peran bank sampah, peran bank sampah dirasa sangat membantu dalam pengurangan sampah terutama sampah non organik. Selain dapat mengurangi sampah juga merupakan pendapatan keluarga bagi nasabah bank sampah. Akan tetapi ini tidak menyelesaikan permasalahan sampah yang dari hari ke hari semakin bertambah. Keberadaan bank sampah sementara ini baru mengurangi sampah tetapi belum menyelesaikan permasalahan sampah.

Menurut Kepala Dinas Lingkungan Hidup Kapubaten Kulon Progo, baru sekitar 10 persen dari total keseluruhan volume sampah di Kulon Progo yang mampu direduksi oleh bank sampah. Walaupun sudah terdapat lebih dari seratus bank sampah di Kulon Progo, namun tidak semua bank sampah masih aktif. Idealnya bank sampah mampu mengurangi 30 persen hingga 50 persen sampah sebelum dikirim ke Tempat Pembuangan Akhir Sampah (TPAS) Banyuroto. Artinya keberadaan bank sampah sebatas memindahkan sampah dari rumah tangga ke bank sampah, atau setidaknya mengurangi sampah di Tempat Pembuangan Akhir (TPA) walaupun tidak secara maksimal.

Sementara itu, menurut Kepala Unit Pelaksana Teknis (UPT) Persampahan, Air Limbah, dan Pertamanan, Dinas Pekerjaan Umum, Perumahan, dan Kawasan Permukiman (DPUPKP) Kulonprogo, dari sekitar 200.000 meter kubik sampah per tahunnya yang dihasilkan di Kulonprogo, hanya 38.394 meter kubik per tahun sampah saja yang bisa tertangani. Bank sampah hanya mampu menangani sampah sekitar 3000 meter kubik saja. Selain itu, data dari Dinas Lingkungan Hidup Kulon progo juga menunjukkan bahwa persebaran bank sampah di tiap daerah tidak merata. Dari 88 desa di Kabuaten Kulon Progo, baru 44 desa yang telah mempunyai bank sampah. Jumlah tersebut bahkan belum mencapai $50 \%$ persentase keseluruhan. Dengan persebaran yang tidak merata ini tentunya akan mengurangi efektiftas bank sampah dalam pengelolaan sampah.

Harapan terhadap bank sampah yang diharapkan mampu menangani persoalan persampahan di Kabupaten Kulon Progo dan mendukung terwujudnya smart city terutama dalam hal smart environment kurang optimal dalam pelaksanaannya. hal ini karena walaupun dengan adanya bank sampah, masih banyak tumpukan sampah yang masih bisa ditemui di Kabupaten Kulon Progo. Selain itu, upaya yang dilakukan pemerintah masih harus diimbangi dengan upaya pengurangan sampah dari lingkup keluarga. Maka dari itu, dapat peneliti Tarik kesimpulan bahwa pengelolaan sampah yang efektif dapat optimal apabila program minim sampah dapat diberlakukan oleh semua masyarakat Kulon Progo mulai dari lingkup keluarga. Program minim sampah dimulai dari rumah tangga dengan cara berusaha untuk tidak menghasilkan sampah dalam kegiatan sehari-hari, karena sampah yang paling banyak didominasi dari sampah dapur. Cara-cara yang dapat dilakukan masyarakat dalam upaya untuk melakukan minim sampah mulai dari lingkup keluarga adalag sebagai berikut:

1. Belanja kebutuhan sehari-hari membawa tempat sendiri agar tidak menghasilkan sampah kantong plastic

2. Memasak, sesuai kebutuhan anggota rumah tangga, artinya tidak membiarkan makanan tersisa dan menjadi sampah

3. Sampah dipilah yang organik dicincang untuk jadi pupuk kompos, sedangkan yang non organik dikumpulkan, dipilah sesuai jenisnya 
dan disetorkan ke bank sampah secara beerkala.

Jika kegiatan minim sampah ini sudah dilakukan setiap rumah tangga, dimana sudah diminimalisir dari rumah tangga dan langsung dilakukan tindakan atas sampah organik dan non organik maka permasalahan sampah akan dapat diatasi dengan baik. Dengan demikian mampu tercipta Kulon Progo smart city, dimana mampu mengolah sampahnya secara baik sebagai wujud terciptanya smart environment dan juga smart people karena masyarakat yang cerdas dalam pengelolaan sampah dan pengendalian sampah.

\section{PENUTUP}

\section{Kesimpulan}

Dari penelitian yang dilakukan, peneliti mengambil kesimpulan bahwa keberadaan bank sampah yang dirahapkan dapat menjadi alternatif pengelolaan sampah di Kulon Progo sehingga mampu menunjang Kulon Progo dalam menciptakan Kulon Progo yang Smart City masih belum efektif. Hal ini karena baru sekitar 10 persen dari total keseluruhan volume sampah di Kulon Progo yang mampu direduksi oleh bank sampah. Itu artinya masih banyak sampah-sampah yang berserakan di tempat-tempat lain yang tidak dikelola dengan baik. Dinas Lingkungan Hidup Kulon Progo juga menyatakan bahwa walaupun keberadaan bank sampah di Kulon Progo sudah mencapai lebih dari 100 bank sampah, namun persoalan sampah di Kulon Progo masih menjadi masalah yang pelik. Hal tersebut dikarenakan masih kurangnya kesadaran masyarakat dalam pengelolaan sampah dan ketersediaan bank sampah yang mampu mencover semua wilayah di Kabupaten Kulon Progo. Selain itu, junlah nasabah bank sampah yang relative masih sedikit yaitu sekitar 2000 nasabah juga menunjukkan bahwa bank sampah masih menjadi sarana yang belum menarik bagi masyarakat.

\section{Saran}

1. Perlunya sosialisasi yang berkelanjutan kepada masyarakat untuk menekan produksi sampah mulai dari keluarga

2. Memberikan edukasi kepada masyarakat bahwa pengelolaan sampah yang baik akan mendorong pencapaian konsep smart city

3. Menambah jumlah bank sampah agar mampu mencover seluruh wilayah di Kabupaten Kulon Progo

\section{DAFTAR PUSTAKA}

Anggraini, D., Pertiwi, M. B., \& Bahrin, D. (2012). Pengaruh Jenis Sampah, Komposisi Masukan dan Waktu Tinggal Terhadap Komposisi Biogas dari Sampah Organik. Jurnal Teknik Kimia, 18(1).

Arjita, U. A. (2017). E-Government Sebagai Bagian Dalam Smart City. In 2nd Seminar Nasional IPTEK Terapan (SENIT).

Asteria, D., \& Heruman, H. (2016). Bank sampah sebagai alternatif strategi pengelolaan sampah berbasis masyarakat di Tasikmalaya (Bank Sampah (Waste Banks) as an alternative of communitybased waste management strategy in Tasikmalaya). Jurnal manusia dan lingkungan, 23(1), 136-141.

DPUPKP. (2019). Produksi sampah di Kulon Progo. Retrieved from https://dpu.kulonprogokab.go.id/a rticle-69-produksi-sampah-di-kulonprogo.html

Fadhilah, A., Sugianto, H., Hadi, K., Firmandhani, S. W., Woro, T., \& Pandelaki, E. E. (2011). Kajian Pengelolaan Sampah Kampus Jurusan Arsitektur Fakultas Teknik Universitas Diponegoro. Modul, 11(2), 62-71.

Kulonprogokab.go.id. (2019). Sistem 
Informasi Bank Sampah Kulon Progo (Sibaku). Retrieved from http://gitdev.kulonprogokab.go.id/ sibaku/\#footer

Lakista, D. A., Saedudin, R. R., \& Lubis, M. (2019). Analisis Dan Perancangan Enterprise Architecture Menggunakan Togaf Adm Pada Fungsi Kebersihan Dalam Sistem Pengelolaan Sampah Berbasis Smart City. eProceedings of Engineering, 6(2).

Malina, A. C., \& Muchtar, A. (2017). Kajian Lingkungan Tempat Pemilahan Sampah Di Kota Makassar. Jurnal Informasi dan Pelayanan Publik Makassar, 1, 14-27.

Mochammad, R. (2019). Inovasi Pelayanan Publik. KEMUDI: Jurnal Ilmu Pemerintahan, 4(1), 1-20.

Mudayana, A. A., Yuli, V., \& Suwartini, I. (2019). Pemberdayaan Masyarakat dalam Pengolahan Limbah Organik. Jurnal Solma, 8(2), 339-347.

Novianty, M. (2013). Dampak Program Bank Sampah Terhadap Sosial Ekonomi Masyarakat Di Kelurahan Binjai, Kecamatan Medan Denai, Kota Medan. Welfare State, 1-16.

Suhendri, S., \& Purnomo, E. P. (2017). Penguatan Kelembagaan Dalam Pencegahan dan Pengendalian Kebakaran Hutan dan Lahan di Kabupaten Muaro Jambi Provinsi Jambi. Journal of Governance and Public Policy, 4(1), 174-204.

Suryani, A. S. (2014). Studi Kasus Bank Sampah Malang (A Case Study of MalangWaste Bank) Anih Sri Suryani. Jurnal Aspirasi, 71-84.

Suswantini, A. L. (2018). Analisis framing literasi lingkungan di kawasan bebas sampah kota bandung. Acta DiurnA, 14(1), 17-27.

Ulfah, N. A., Normelani, E., \& Arisanty, D. (2016). Studi Efektifitas Bank Sampah sebagai Salah Satu Pendekatan dalam
Pengelolaan Sampah Tingkat Sekolah Menengah Atas (SMA) di Banjarmasin. JPG (Jurnal Pendidikan Geografi), 3(5).

Wahyudi, D. T., Putro, S. (2019). Roadmap Smart City Kota Malang. Jurnal Pangripta, Vol.1 No., 307-320. 